\title{
Accuracy in size judgments as a function of location in the visual field and the duration of viewing ${ }^{1}$
}

ALBERT S. RODWAN EMOR Y UNIVERSITY ${ }^{2}$
This study compared the effect of varying the duration of of viewing and the location of the stimulus in the visual field. The duration of viewing varied from $1 \mathrm{msec}$ to $1.00 \mathrm{sec}$ in four equal log steps. The location parameter varied from having a fixation point and a reduction tube to presenting the stimulus randomly at five different locations on the screen. There was no effect due to duration of viewing, nor to location, but there was an effect due to the interaction between them. The interaction was due to a linear trend in the most extreme location condition.

One of the reasons for studying perception under poor viewing conditions is that this will reduce performance and thereby allow various mechanisms to manifest themselves. This class of studies has been called "stimulus impoverishment" and was surveyed by Hake (1957).

A typical way of decreasing performance is by restricting the duration of viewing. Freeman (1929) constructed inkblots as stimuli and varied the duration of viewing. He reported that the perceptual system went through three stages of development. The first stage he called "the pre-perceptive determination"; this stage involved the vague or general impression of "something out there." The second stage he called "perceptive particularity"; in this stage the $O$ could determine that there was something out there. The contours were clearer and the existence of a pattern was evident. In the final stage, which he called "perceptive familiarity," the $O$ could identify the figure. Moore (1910) used nonsense figures and reported a gradual development of perception as a function of the duration of viewing. He found a fourth stage which came after the identification stage. The fourth stage was involved in the problem of orientation. His Os reported on orientation after they had correctly recognized the figures. Dickinson (1926) reported three stages in the development of perception over time. His three stages were "visual pattern," "generic object," and "specific object."

Nesmith \& Rodwan (1967) found no change in perceptual performance as a function of the duration of viewing. They presented 100 different plane figures and required Ss to make judgments of form (square-rectangle) or size (large-small). The duration of viewing varied from 1 msec to $1.28 \sec (1,5,10,20,40,80,160,320,640$, and $1280 \mathrm{msec}$ ). They found no effect due to duration of viewing on either the form judgment or the size judgment, nor did they find any interaction between type of judgment and duration of viewing. The only difference found was due to type of judgments; form judgments were significantly better than size. They concluded that the so-called duration effect might be subsumed under a more general principle; namely, it takes time to orient the visual system toward the stimulus.

The following study is a test of Nesmith and Rodwan's hypothesis.

\section{Method}

Subjects. Ten students, five males and five females, were used in this experiment. They were obtained as volunteers and were paid 20.00 dollars at the end of the experiment. Each $S$ had a corrected visual acuity of at least $20 / 20$ in both eyes.

Apparatus and stimuli. The stimulus set consisted of 100 slides of plane, right-angle parallelograms. There were 10 heights and 10 widths. The projected stimuli varied from 10.10 in. to 12.25 in. both vertically and horizontally, in 25 in. increments with a maximum error less than $1 / 32$ in. Each stimulus was on its own slide and was projected onto a screen from a distance of about $10 \mathrm{ft}$. The screen was a standard projection screen (40 in. high and $50 \mathrm{in.} \mathrm{wide).} \mathrm{The} \mathrm{stimulus} \mathrm{appeared} \mathrm{on}$ the screen as a bright patch in a dark surround (there were no facilities for measuring light available; a $300 \mathrm{~W}$ projection bulb was the only light source).

During a trial the experimental room was dark except for the light from the slide projector. When the trial ended three lights came on: two overhead $150 \mathrm{~W}$ bulbs and a $25 \mathrm{~W}$ bulb at S's side. The purpose was two-fold: (a) to control for after images, and (b) to avoid glare when $\mathrm{S}$ wrote down his response.

Experimental conditions and design. There were four treatment conditions and four durations of viewing. The total number of sessions was 16. All Ss went went through all of the conditions in a different random order, and the stimuli were presented in a different order to each of the Ss. Thus, the design was a withinSs design with each $S$ as a replication.

The four treatment conditions were used to test the hypothesis that location, and not duration, can serve as a basis for the time dependence effects. Consequently, the conditions were designed to distinguish location effects from a true time dependence. Condition A maximized the information about the location of the stimulus. A short reduction tube was used to reduce the possibility that $S$ would attend to the edge of the screen and use the edge as a basis for making his judgments. The tube was positioned so that it just cut off the edge. When the session began, $\mathrm{S}$ positioned the tube so that all he could see was the screen. A second projector was used to give a point of light which served as a 


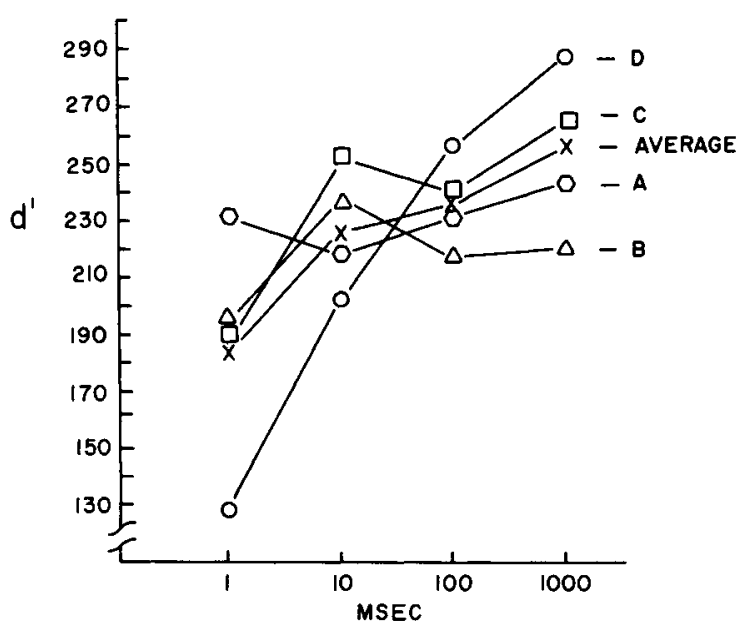

Fig. 1. Performance as a function of duration of viewing. The four lettered curves refer to the four location parameters. The curve marked "average" is the mean of the four location curves.

fixation point. The fixation point was on between trials and was timed to go off 1 sec prior to the presentation of the next stimulus. The fixation point was located so that it coincided with the center of the stimulus figure. The sequence of events in a trial was as follows: the stimulus came on for the prescribed duration; when it went off, $S$ moved his head away from the tube, made the verbal judgment ("large" or "small"), and wrote down that judgment on his own data paper. This was followed by $S$ repositioning himself and readjusting the tube. Then $\mathrm{E}$ said "ready" and turned off the fixation light. One sec later, the next stimulus came on. Condition B was exactly the same except for the absence of the reduction tube. Condition $C$ had no reduction tube and no fixation point. Condition D had no reduction tube, no fixation point, and no ready signal. Furthermore, in Condition $D$ the stimulus could appear in any one of five locations on the screen: upper left, upper right, lower left, lower right, and center.

Procedure. Each S was run individually and, except in unusual conditions, was run at the same time on successive days. There were exceptions to this schedule, but they did not produce a measurable effect. Each session began with 20 unrecorded trials. These were called practice trials and were used as an aid to $S$ in stabilizing his criterion for that condition. At the beginning of each session, $\mathrm{S}$ was reminded that he was to respond as soon as the stimulus was turned off and that he was to make a size judgment of "large" or "small."

Resulis

A three way analysis of variance with one measure in each cell was performed (Lindquist, 1956, p. 100). There was no effect due to either duration of viewing $(F=1.50, \mathrm{df}=3 / 27, \mathrm{p}>.05)$ or location conditions $(F=$ 1.54, $\mathrm{df}=3 / 27, p>.05)$. The only effect that reached significance was the interaction $(F=2.71, d f=9 / 27$, $\mathrm{p}<.05)$.
A further analysis was performed to test for the cause for the interaction. A regression analysis was done on conditions $\mathrm{A}, \mathrm{B}$, and $\mathrm{C}$ to test whether or not they had a common slope of zero. The regression analysis gave an $F=2.40, d f=1 / 116, p>.05$.

The common slope is in effect zero; none of the three slopes differ significantly from zero. A second regression analysis was performed on the slope of Condition $D$. This gave an $F=10.37, d f=1 / 29, p<.01$. A further test for deviation from linearity, gave an $F=1.29$, df $=9 / 29, p>.05$. We can conclude that Condition $D$ was the only condition which had a slope different from zero; furthermore, the curve was linear.

Figure 1 is a plot of $d^{\prime}$ as a function of duration of viewing. This plot depicts, graphically, the results of the several analyses.

\section{Discussion}

These data do not support the position that duration of viewing is correlated with perceptual performance. Such a view would have predicted that all the conditions must have a significant slope. This lack of confirmation of a view which has a long history raises certain problems, and requires a detailed explanation.

One possible explanation for the lack of confirmation of any time dependence in perception is that the older studies which investigated the time dependence notion were methodologically weak. Flavell \& Draguns (1957) reviewed a great deal of the literature and stated that it was "quite poor by present-day-standards." Pollack \& Chaplin (1962) presented a similar argument. They pointed out that time dependence studies had many flaws.

A second possible explanation of these results is that offered by Nesmith \& Rodwan (1967). Duration of viewing may not be a very important parameter in itself; rather, it may operate so as to allow other events to influence the effect of impoverishing the stimulus array.

\section{References}

DICKINSON, C. A. Experience and visual perception. Amer. J. Psychol, 1926, 37, 330-344.

FLAVELL, J. H., \& DRAGUNS, J. A. A microgenetic approach to perception and thought. Psychol Bull., 1957, 54, 197-217.

FREEMAN, G. L. An experimental study of the perception of objects J. exp. Psychol., 1929, 12, 340-358.

HAKE, H. W. Contributions of psychology to the study of pattem vision. WADC technical report No. 57-621, 1957.

MOORE, T. V. The process of abstraction. University of California Publications in Psychology, 1910-1916, 1, 73-197.

NESMITH, H. R., \& RODWAN, A. S. The effect of durational viewing on form and size judgments. $J$. exp. Psychol., in press.

POLLACK, R. H., \& CHAPLIN, M. R. Problems in microgenetic investigation. Amer. J. Psychol., 1962, 75, 495-498.

SWETS, J. A., TANNER, WILSON, Jr., \& BIRDSALL, T. G. Division processes in perception. Psychol Rev., 1961, 68, 301-340.

\section{Notes}

1. This research was supported, in part, by funds from the National Institutes of Health, Grant No. MH 11210-02.

2. Now at De Paul University, Chicago, Illinois. 